Research papers

\title{
Downscaling near-surface soil moisture from field to plot scale: A comparative analysis under different environmental conditions
}

\author{
Paolo Nasta $^{\mathrm{a}, *}$, Daniele Penna ${ }^{\mathrm{b}}$, Luca Brocca ${ }^{\mathrm{c}}$, Giulia Zuecco ${ }^{\mathrm{d}}$, Nunzio Romano ${ }^{\mathrm{a}}$ \\ ${ }^{a}$ Dept. of Agricultural Sciences, AFBE Division, University of Napoli Federico II, Portici, Napoli, Italy \\ ${ }^{\mathrm{b}}$ Dept. of Agricultural, Food and Forestry Systems, University of Florence, Italy \\ ${ }^{\mathrm{c}}$ Research Institute for Geo-Hydrological Protection, National Research Council, Perugia, Italy \\ ${ }^{\mathrm{d}}$ Dept. of Land, Environment, Agriculture and Forestry, University of Padova, Legnaro, Italy
}

\section{A R T I C L E I N F O}

\section{Article history:}

Received 11 September 2017

Received in revised form 1 December 2017

Accepted 4 December 2017

Available online 6 December 2017

This manuscript was handled by Marco

Borga, Editor-in-Chief

\section{Keywords:}

Soil moisture

Spatial resolution

Topography

Time domain reflectometry (TDR)

Equilibrium Moisture from Topography

(EMT)

Seasonality

Temporal instability

Aridity index

\begin{abstract}
A B S T R A C T
Indirect measurements of field-scale (hectometer grid-size) spatial-average near-surface soil moisture are becoming increasingly available by exploiting new-generation ground-based and satellite sensors. Nonetheless, modeling applications for water resources management require knowledge of plot-scale (1-5 m grid-size) soil moisture by using measurements through spatially-distributed sensor network systems. Since efforts to fulfill such requirements are not always possible due to time and budget constraints, alternative approaches are desirable. In this study, we explore the feasibility of determining spatial-average soil moisture and soil moisture patterns given the knowledge of long-term records of climate forcing data and topographic attributes. A downscaling approach is proposed that couples two different models: the Eco-Hydrological Bucket and Equilibrium Moisture from Topography. This approach helps identify the relative importance of two compound topographic indexes in explaining the spatial variation of soil moisture patterns, indicating valley- and hillslope-dependence controlled by lateral flow and radiative processes, respectively. The integrated model also detects temporal instability if the dominant type of topographic dependence changes with spatial-average soil moisture. Model application was carried out at three sites in different parts of Italy, each characterized by different environmental conditions. Prior calibration was performed by using sparse and sporadic soil moisture values measured by portable time domain reflectometry devices. Cross-site comparisons offer different interpretations in the explained spatial variation of soil moisture patterns, with time-invariant valley-dependence (site in northern Italy) and hillslope-dependence (site in southern Italy). The sources of soil moisture spatial variation at the site in central Italy are time-variant within the year and the seasonal change of topographic dependence can be conveniently correlated to a climate indicator such as the aridity index.
\end{abstract}

(c) 2017 Elsevier B.V. All rights reserved.

\section{Introduction}

Near-surface soil moisture $(\theta)$ is a key indicator of hydrological response and a linking variable in the relationships among climate, soil, topography, and vegetation (Western et al., 2004; Wilson et al., 2004). Local knowledge of soil moisture dynamics is crucial for improving water management strategies and setting up optimal use of available water resources (Romano, 2014; Vereecken et al., 2015). Hydrological processes such as evapotranspiration and surface runoff are highly nonlinear and are controlled by near-surface soil moisture which, in turn, necessitates its inherent

\footnotetext{
* Corresponding author at: Department of Agricultural Sciences - Division of Agricultural, Forest and Biosystems Engineering, University of Naples Federico II, Via Università 100, Portici, Italy.

E-mail address: paolo.nasta@unina.it (P. Nasta).
}

variability to be properly described over a variety of spatiotemporal scales (Blume et al., 2009; Swarowsky et al., 2011; Mittelbach and Seneviratne, 2012; Penna et al., 2013; Poltoradnev et al., 2016). Several studies report local and nonlocal biophysical controls affecting soil moisture patterns across different spatial scales (Famiglietti et al., 2008; Joshi and Mohanty, 2010; Zhao et al., 2011; Brocca et al., 2012; Shin and Mohanty, 2013; Qiu et al., 2014; Zucco et al., 2014). The relations between soil moisture and the readily available digital terrain data assumed as basic key-controlling factors have been extensively investigated (Beaudette et al., 2013; Hu and Si, 2014; Qu et al., 2015; Schröter et al., 2015). Other biophysical factors, such as soil properties, vegetation characteristics, and anthropogenic disturbance (e.g. tillage), additionally enhance the spatio-temporal variability of soil moisture patterns (Jonard et al., 2013; Gaur and Mohanty, 2013; Dimitrov et al., 2015). 
Indirect measurements of soil moisture are becoming either intermittently accessible (low temporal resolution, $>1$ day) or continuously available (high temporal resolution, $\leq 1$ day) at the field (e.g. cosmic ray technology, measurement circle with diameter of about 500-600 m) to the regional scale (e.g. remote sensing, pixel dimension of 10-40 km) (Romano, 2014; Brocca et al., 2017; Mohanty et al., 2017). Many applications, such as water resources planning, soil management, subsurface contaminant transport, precision agriculture, just to mention a few, require spatially distributed information of plot-scale soil moisture (e.g. meter grid size, 1-5 m). A large number of near-real-time on-site measurements (e.g. wireless sensor networks) is necessary in order to develop optimal prevention, mitigation, and adaptation strategies for soil erosion control, flood forecasting, afforestation programs after wildfires, and assessment of contaminant transport to the groundwater (Meyles et al., 2003; Cosh et al., 2004; Hoehn et al., 2017). However, such dense-information systems require excessive costs, time, and efforts for their installation and maintenance. Before installing a sensor network, it is extremely useful to infer whether or not soil moisture patterns are controlled by either radiation-related or flow-related topographic variables. This is prognostic information enabling the sensors to be optimally positioned in a field plot. Therefore it is necessary to develop suitable methods for capturing these smaller scale insights while having data available at larger spatial scales (spatial scale transfer approach). Solving this top-down spatial scale mismatch forms part of the so-called downscaling problem, which, in brief, involves the use of auxiliary data to retrieve the desired fine-scale fluctuations and heterogeneities of a certain variable given its spatiallyaveraged values at a larger scale (Vereecken et al., 2008; Vereecken et al., 2014; Pachepsky and Hill, 2017; Peng et al., 2017).

Some existing downscaling methods are based on knowledge of several terrain attributes, which are often easily obtained from already available digital elevation models (DEMs) (Perry and Niemann, 2007; Korres et al., 2010; Busch et al., 2012; Coleman and Niemann, 2012; Werbylo and Niemann, 2014). Coleman and Niemann (2013) proposed the Equilibrium Moisture from Topography (EMT) model to downscale spatial-average soil moisture values by exploiting information on topographic attributes only. The EMT model was subsequently upgraded by including spatial information about soil and vegetation characteristics (Ranney et al., 2015) across different spatial scales (Cowley et al., 2017; Hoehn et al., 2017). This physically-sound model provides metrics to define the dominant type of topographic indexes in explaining the spatial variation of soil moisture patterns. In other words, radiation-related and flow-related topographic variables determine whether hillslope dependence or valley dependence is the dominant organization type. Under the above circumstances, we also define temporal instability of soil moisture patterns as the seasonal (intra-annual) change of topographic dependence. If a soil moisture data set exhibits temporal instability, we question the role of climatic seasonality. Our main hypothesis is that valley pattern (flow-related topographic index) should be dominant in the humid season whereas hillslope pattern (radiative-related topographic index) should be more important during the dry season.

The above-mentioned downscaling procedures rely on the availability of spatial-average soil moisture data. If this is not the case, such as when future scenarios need to be developed or there is a lack of historical time series, we hereby propose to obtain surrogate values through the use of a simplistic hydrological model. Bucket-filling models estimate soil moisture by using long records of boundary forcing data and a few lumped parameters for soil and vegetation characteristics (Laio et al., 2001; Bergström and Lindström, 2015; Castillo et al., 2015).

In this study, we adopt the bucket model proposed by Guswa et al. (2002) and we name it as "Eco-Hydrological Bucket" (EHB) in the remainder of the paper. The experimental field mimics a bucket requiring boundary forcing, i.e., precipitation and potential evapotranspiration, as input data. Our investigation aims to couple the EHB and EMT models in order to relate boundary forcing data to spatial-average soil moisture which, in turn, is used with readily-available topographical attributes for estimating spatially distributed soil moisture values. The major goal of the present paper is twofold: $i$ ) to calibrate and test the performance metrics of the proposed downscaling approach at three sites located in northern, central, and southern Italy under different climatic and topographical conditions; ii) to relate climatic seasonality to the dominant type of topographic dependence affecting temporal instability (if detected) of simulated soil moisture patterns.

The paper is organized as follows: Section 2 briefly describes the three experimental sites and the model set-up whereas Section 3 presents calibration and validation of the EHB and EMT models. In Section 4 we analyze the topographic dependence of soil moisture patterns and their relationship with seasonal values of a climate indicator (Aridity Index, AI). The conclusive remarks are finally presented in Section 5 .

\section{Methods and experimental works}

\subsection{Data sets in the three experimental sites}

The three test sites are located in Italy along an ideal transect that crosses different local climatic zones (Fig. 1). Terrain attributes were retrieved from the available digital elevation models (DEM) with different resolutions (see Table 1).

The first site known as "Piramide" (hereinafter PIR) is positioned along a divergent-convex hillslope in the lower part of the Rio Vauz catchment which belongs to the Italian Dolomites (the Veneto Region in northern Italy) (Penna et al., 2009; Penna et al., 2011; Penna et al., 2013). The size of the field is 0.46 ha, the elevation range is $1936-1986 \mathrm{~m}$ a.s.l., and the dominant land use is alpine grassland. Mean annual precipitation is $1.02 \mathrm{~m}$, half of which consists in snowfall (the snow-free period spans from May till October). The climate is typically alpine. Soil depth assessed through depth-to-refusal measurements was on average $1.1 \mathrm{~m}$. The highest content in organic matter was found in the first $0.10 \mathrm{~m}$ of the soil profile and soil porosity ranged from $45 \%$ to 70.5\% (Penna et al., 2015). Recurrent field campaigns were carried out in the summer season of 2005, 2006 and 2007 in order to measure surface soil moisture on a grid of 26 points by using a portable time domain reflectometry device (TDR300, Spectrum Technologies Inc., USA) connected to probes with metallic rods $0.12 \mathrm{~m}$ long.

The second site called "Ingegneria" (hereinafter ING) is located in the Upper Tiber Valley in the Region of Umbria (central Italy). A detailed description of this experimental area can be found in Brocca et al. (2007) and Brocca et al. (2009). The climate is subcontinental Mediterranean with mean annual rainfall of about $0.83 \mathrm{~m}$. Land use is grassland, and soil texture of the uppermost soil layer is silty clay loam. Surface soil moisture values were measured in 14 measurement campaigns (February to May 2004) by following a regular grid of 50 points. Near-surface soil moisture was determined by using a portable TDR unit (Soilmoisture Equipment Corporation TRASE ${ }^{\circledR}$ TDR) connected to probes with metallic rods $0.15 \mathrm{~m}$ long.

The third site is a small catchment located near the village of Monteforte Cilento in the Region of Campania (southern Italy) (Nasta et al., 2013). It is denoted by the acronym MFC1 and belongs to the Upper Alento River Catchment (Nasta et al., 2009; Nasta et al., 2017). The climate is sub-humid Mediterranean with hotdry summers and mild-wet winters. The MFC1 catchment is divided into private landholdings with different land uses (arable 

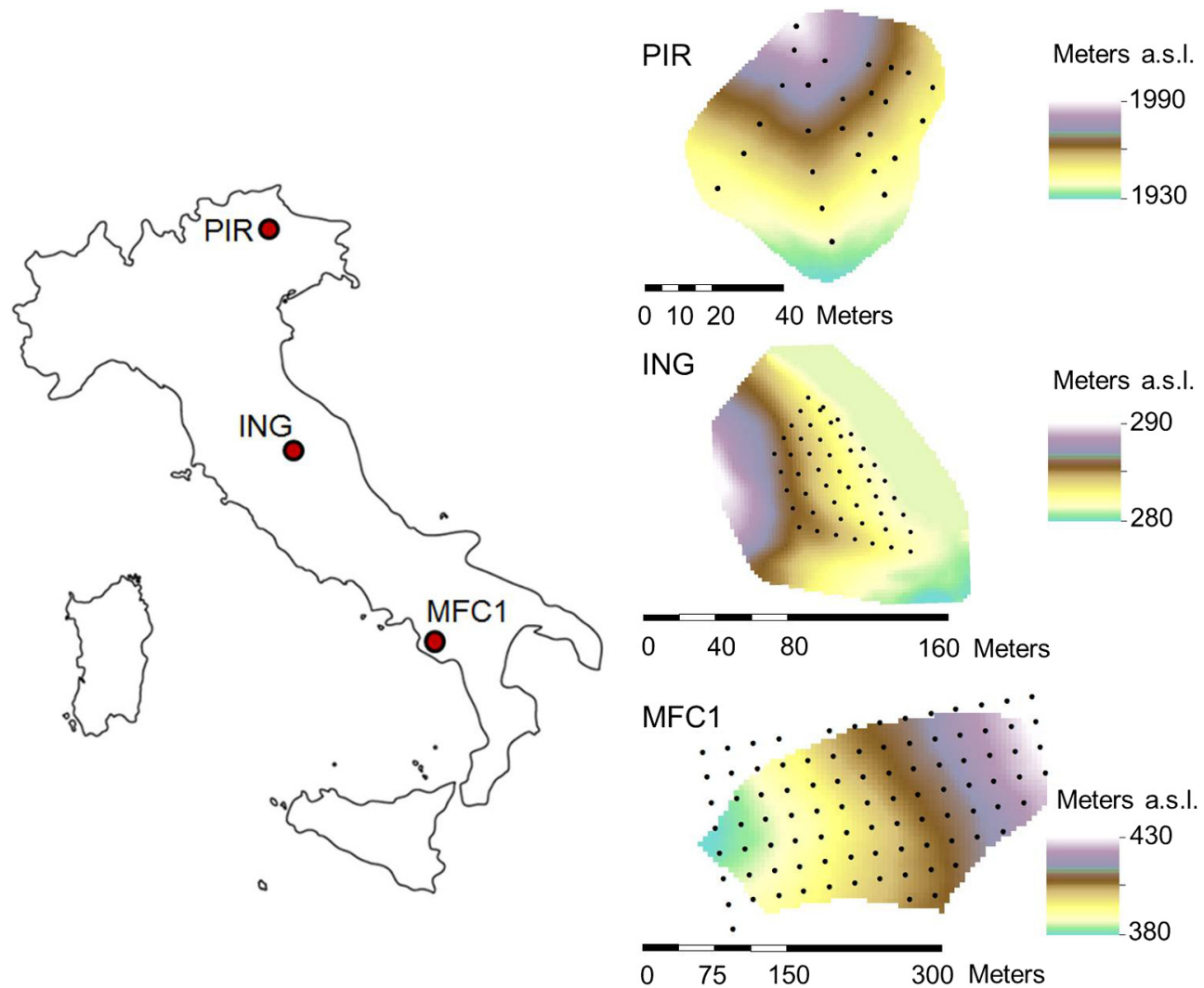

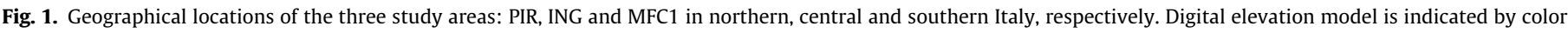
ramp and given in meters a.s.l.. The schematic representation of soil moisture sampling points (black dots) is illustrated at each site.

Table 1

Summary of climatic and topographical features, dominant soil textural classification, land-use and organization of measurement surveys.

\begin{tabular}{|c|c|c|c|c|}
\hline & & PIR & ING & MFC1 \\
\hline Average annual $R$ & $(\mathrm{~m})$ & $1.02^{\dagger}$ & 0.83 & 1.16 \\
\hline Average annual $E T_{\max }$ & $(\mathrm{m})$ & 0.48 & 0.92 & 1.03 \\
\hline Years of climate forcing data & (yr) & 32 & 47 & 55 \\
\hline Field area & (ha) & 0.46 & 1.39 & 4.63 \\
\hline DEM grid size & $(\mathrm{m})$ & 1 & 2 & 5 \\
\hline Average elevation & $(\mathrm{m})$ & 1958 & 285 & 402 \\
\hline Average slope gradient & $(\%)$ & 33.0 & 4.1 & 7.1 \\
\hline Soil textural class & & Clay loam & Silty clay loam & Clay loam \\
\hline Land-use & & Grassland & Grassland & Arable and pasture \\
\hline Number of sampling points & & 26 & 50 & 94 \\
\hline Measurement days & & 71 & 14 & 13 \\
\hline
\end{tabular}

$\dagger$ Snowfall is ignored in the computation of the average annual $\mathrm{R}$.

and pasture). Measured soil textural and physical properties are reported in Nasta et al. (2013). The uppermost soil horizon belongs to the clay loam textural class and is characterized by macroporosity and presence of gravels and stones. Near-surface soil moisture values were measured with a portable TDR device (TDR100, Campbell Scientific Inc., USA) using a $25 \mathrm{~m} \times 25 \mathrm{~m}$ 94-point regular grid over 13 days (from September 1st 2006 to April 24th 2008). The TDR device, along with the supply battery, was fitted in a backpack and connected to the probes (consisting of metallic rods $0.15 \mathrm{~m}$ long) manufactured at the Laboratory of Soil Hydrology of the University of Naples Federico II (Italy). The measurements were controlled by a handheld PC.

Historical records of daily rainfall $(R)$ and temperature were retrieved from three weather stations located in close proximity to the experimental sites. Reference evapotranspiration $\left(E T_{\max }\right)$ was calculated by following the protocol proposed by Hargreaves et al. (1985). Information on climate, topography, soil, and vegetation characteristics, as well as measurement surveys pertaining to each experimental site, are summarized in Table 1 . The long records of $R$ and $E T_{\max }$ were aggregated in average annual values in the three sites, even though daily climate forcing data were used in the simulations described below. We chose to ignore snowfall at site PIR where conditions are humid due to frequent occurrences of rainfall in the summer and also to very low evapotranspiration fluxes. The other two sites are characterized by the typical seasonality of the Mediterranean climate with warm-dry summers and mild-wet winters.

\subsection{Set-up of the conceptual modeling and hypothesis-driven strategy}

Fig. 2a graphically illustrates the modeling approach that conceptualizes the downscaling procedure by converting field-scale 
a)

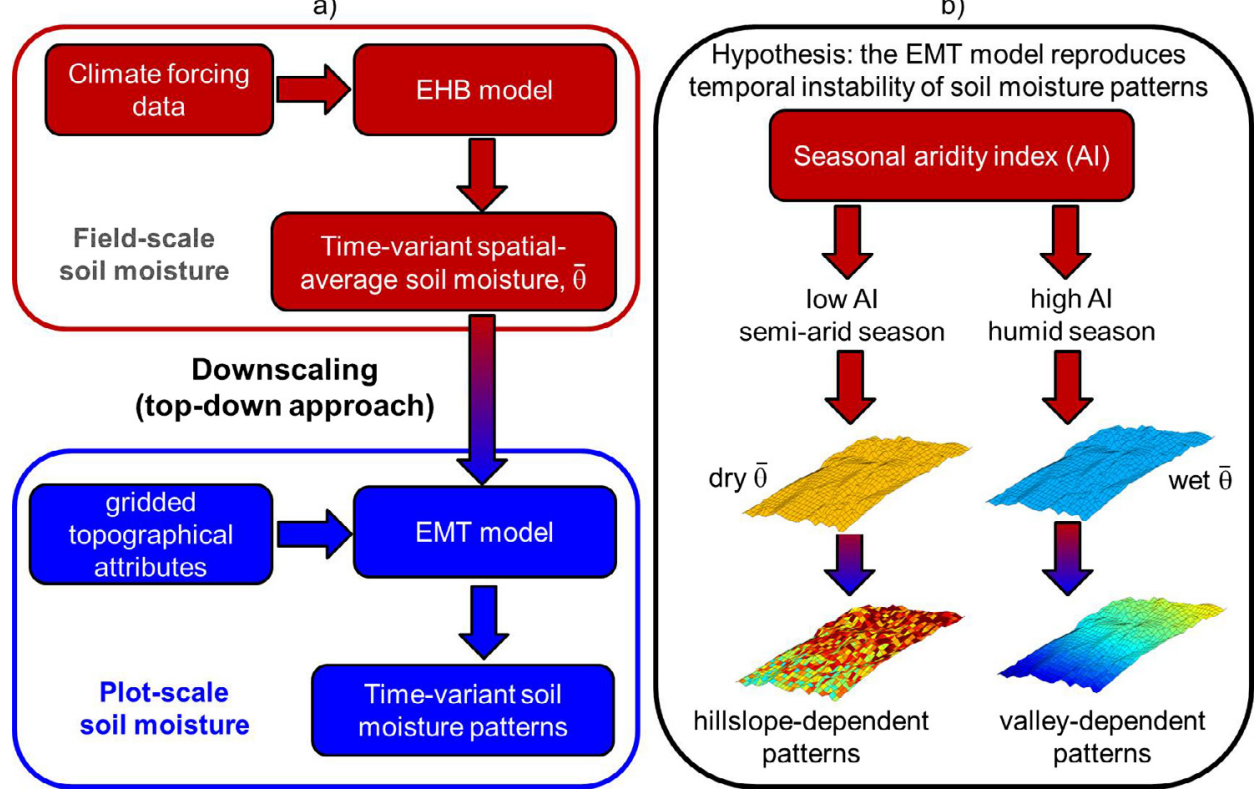

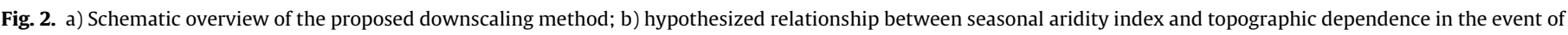
soil moisture patterns exhibiting temporal instability.

spatial-average soil moisture (garnet-colored boxes) into spatially - distributed plot-scale soil moisture patterns (blue boxes). In this study we refer to field and plot as spatial scales with hectometer and meter grid sizes, respectively. If the field area is sufficiently small, we can conveniently assume that soil and vegetation parameters are fairly uniform. Time-variant spatial-average soil moisture is obtained by using the Eco-Hydrological Bucket (EHB) model and climate forcing data as inputs.

Time-variant soil moisture patterns are then estimated through the Equilibrium Moisture from Topography (EMT) model by using field-scale soil moisture and gridded values of topographic attributes. In other words, spatial-average soil moisture values (i.e., the EHB-model output) simulated under long-term climate forcing data are used as input for the EMT model. The EMT model is able to quantify the relative importance of valleydependent (flow-related topographic attributes) and hillslopedependent (radiation-related topographic attributes) soil moisture patterns. Moreover, this model enables the time stability or instability of soil moisture patterns to be identified whether a dominant type of topographic dependence is time-invariant or time-variant, respectively. The basic hypothesis is that climate seasonality (cyclical alternation of dry and wet conditions within the year) is related to the switching between hillslope-dependent and valley-dependent soil moisture patterns if the EMT model reproduces temporal instability (Fig. 2b). Therefore, if the assumption of detecting temporal instability by the EMT model is valid, the following scientific question arises: "what is the relationship between seasonal climate indicators and the dominant type of topographic dependence?". To tackle this problem, we chose the FAO aridity index (AI), i.e. the ratio between rainfall and reference evapotranspiration, as a climate indicator enabling the seasonal climate patterns to be classified (Food and Agriculture Organization of the United Nations, 1977; Cheval et al., 2017). Spinoni et al. (2015) provide the main AI classes in their Table 1: arid $(0.05<\mathrm{AI}<0.2)$, semi-arid $(0.2<\mathrm{AI}<0.5)$, dry $(0.5<\mathrm{AI}<$ $0.65)$, sub-humid $(0.65<\mathrm{AI}<0.75)$, humid ( $\mathrm{AI}>0.75$ ) and cold $\left(\mathrm{ET}_{\max }<400 \mathrm{~mm}\right)$. Below we investigate the empirical relationship between seasonal variation of AI and time-variant topographic dominance of soil moisture patterns.
Both models require calibration by using direct multiple-point measurements of soil moisture data. The unknown parameter sets of models EHB and EMT are calibrated by comparing observed and simulated spatial-average soil moisture and soil moisture patterns, respectively. We specify that also for calibration purposes the input in the EMT model is represented by the output of the EHB model in order to guarantee the combined model performance and consider uncertainty propagation from EHB to EMT.

\subsection{EHB model}

The lumped soil-water balance in each of the three experimental fields is modeled through a single-layer bucket-type model (spatially zero-dimensional) described by the following equation (Guswa et al., 2002):

$\phi z_{r} \frac{d S}{d t}=I(S, t)-L(S)-E(S)-T(S)$

where $\phi\left(\mathrm{m}^{3} \mathrm{~m}^{-3}\right)$ is soil porosity, $z_{r}(\mathrm{~m})$ is the hydrologically effective rooting depth, $S=\theta / \phi$ is unitless and represents the soilwater saturation ratio averaged over the root zone, and $I(S, t)$ is the infiltration rate, whereas $L(S), E(S)$, and $T(S)$ are vertical drainage (or downward leakage from the bottom part of the soil profile), actual evaporation, and actual transpiration, respectively. All of these variables are expressed in units of $\mathrm{m} \mathrm{d}^{-1}$. The input data are daily rainfall $(R)$ and reference evapotranspiration $\left(E T_{\max }\right)$. Rainfall entering the modeled bucket is entirely converted into $I$ until the root zone fills to saturation excess. Infiltration excess is turned into runoff. Water losses $(L, E$, and $T$ ) from the modeled bucket depend on soil hydraulic characteristics, as described in Guswa et al. (2002), which are unknown and need to be calibrated. Such soil hydraulic parameters are saturation at or below which evaporation ceases (hygroscopic saturation, $S_{h}$ ), saturation at or below which transpiration is zero and the plant wilts (wilting point, $S_{w}$ ), saturation at and below which both evaporation and water root uptake stress begins $\left(S^{*}\right)$, saturation below which drainage stops (soil saturation at the condition of field capacity, $S_{f c}$; see Romano et al., 2011). Other unknown parameters describing the soil hydraulic properties are the vertical saturated hydraulic con- 
ductivity $\left(K_{s, v}\right)$ and the vertical pore disconnectedness index $\left(\gamma_{v}\right)$. The model outputs consist of daily $L, E$, and $T$ rates, in addition to the average root-zone soil saturation $(S)$ which is then converted into a average root-zone soil moisture, $\theta=S \phi$. We assume that $\theta$ and $S$ are representative values over the entire study area and will be referred to as $\bar{\theta}$ and $\bar{S}$, respectively.

Water that infiltrates into the soil control volume is distributed uniformly over the effective rooting depth at the end of each rainfall event. Indeed, this bucketing conceptualization ignores the vertical distribution of soil moisture within the hydrologically active soil zone, and thus provides only an average saturation over the entire rooting depth. The three experimental sites are mostly covered by short vegetation with roots that are dense closer to the soil surface. Therefore we implicitly make the crude assumption of modeling a relatively shallow effective rooting depth. For calibration purposes, the EHB-modeled and TDR-measured soil moisture can be consistently compared only if the modeled soil depth is assumed equal to the length of metallic rods belonging to the TDR sensors employed during the measurement campaigns.

\subsection{EMT model}

As input, the EMT model uses gridded terrain attributes (slope, potential solar radiation index, surface curvature and contributing area) and spatial-average soil moisture values (simulated by the EHB model) in order to estimate grid-cell soil moisture pertaining to the study area. Soil and vegetation characteristics are conveniently assumed as spatially uniform, an assumption which seems reasonable based on actual field observations and also considering the relatively small area of the three experimental sites. The EMT model is based on the water balance in the hydrologically active layer (assumed with depth equal to $z_{r}$ ) by assuming equilibrium between inflows and outflows. Soil moisture at a given location is computed through the following equation (Coleman and Niemann, 2013):

$\theta=\frac{w_{G} \theta_{G}+w_{L} \theta_{L}+w_{R} \theta_{R}+w_{A} \theta_{A}}{w_{G}+w_{L}+w_{R}+w_{A}}$

where $\theta_{G}, \theta_{L}, \theta_{R}, \theta_{A}$ are the estimates of soil moisture subjected to drainage, lateral flow (i.e. slope parallel), radiative evapotranspiration (ET) term and aerodynamic ET term, respectively. The terms $w_{G}, w_{L}, w_{R}, w_{A}$ denote the weights of each estimate. Only lateral flow and radiative ET term vary in space with topography and are therefore able to reproduce soil moisture patterns. The lateral flow process explains valley-dependent soil moisture patterns whereas the radiative ET term is linked to the solar radiation index and aspect-related attributes and hence prevails over hillslopedependent soil moisture patterns. Drainage and aerodynamic ET term reproduce spatial-average soil moisture $(\bar{\theta})$ patterns since they do not depend on topography. The equations explaining the abovementioned terms are as follows.

Soil moisture $\left(\theta_{G}\right)$ and weight $\left(w_{G}\right)$ related to drainage are defined as:

$\theta_{G}=\bar{\theta}$

$w_{G}=K_{s, v}\left(\frac{\bar{\theta}}{\phi}\right)^{\gamma_{v}}$

where soil porosity $(\phi)$, vertical saturated hydraulic conductivity $\left(K_{s, v}\right)$ and the vertical pore disconnectedness index $\left(\gamma_{v}\right)$ are defined in Section 2.3.

Soil moisture $\left(\theta_{L}\right)$ and weight $\left(w_{L}\right)$ related to lateral flow are defined as:
$\theta_{L}=\frac{\bar{\theta}}{\Lambda}\left(\frac{A}{c S_{L}^{\varepsilon}}\right)^{1 / \gamma_{h}}\left(\frac{\kappa_{\min }}{\kappa_{\min }-\kappa}\right)^{1 / \gamma_{h}}$

where $A$ is the contributing area, $c$ is the contour length, $S_{L}$ is the topographic slope, $\varepsilon$ is an empirical parameter relating the hydraulic gradient to $S_{L}, \kappa_{\min }$ is the minimum curvature for which the hydrologically active layer is present, $\kappa$ is the local total surface curvature, $\gamma_{h}$ is the horizontal pore disconnectedness, and $\Lambda$ is the spatial-average value of the lateral flow index (LFI). The LFI is the first compound topographic index defined as follows:

$L F I=\left(\frac{A}{c S_{L}^{\varepsilon}}\right)^{1 / \gamma_{h}}\left(\frac{\kappa_{\min }}{\kappa_{\min }-\kappa}\right)^{1 / \gamma_{h}}$

$w_{L}=\frac{Z_{r} K_{s, h}}{\Lambda^{\gamma_{h}}}\left(\frac{\bar{\theta}}{\phi}\right)^{\gamma_{h}}$

where $K_{s, h}$ is the saturated horizontal hydraulic conductivity. The LFI varies in space because $A, S_{L}$ and $\kappa$ vary with topography.

Soil moisture $\left(\theta_{R}\right)$ and weight $\left(w_{R}\right)$ related to radiative ET term are defined as:

$\theta_{R}=\frac{\bar{\theta}}{\Pi}\left(\frac{1}{I_{p}}\right)^{1 / \beta_{r}}$

where $I_{p}$ is the potential solar radiation index defined as the ratio of the insolation of the topographic surface relative to that of a horizontal surface at the same location and date. Moreover, $\beta_{r}$ is an empirical vegetation parameter featuring in the radiative ET term, $\Pi$ is the spatial-average value of the evapotranspiration index (ETI) which is the second compound topographic index, defined as:

$E T I=\left(\frac{1}{I_{p}}\right)^{1 / \beta_{r}}$

$w_{R}=\frac{E T_{\max }}{(1+\alpha) \Pi^{\beta_{r}}}\left(\frac{\bar{\theta}}{\phi}\right)^{\beta_{r}}$

where $\alpha$ is the ratio of the aerodynamic term to the radiation term. The ETI varies in space because $I_{p}$ varies with topography.

Soil moisture $\left(\theta_{A}\right)$ and weight $\left(w_{A}\right)$ related to aerodynamic ET term are defined as:

$\theta_{A}=\bar{\theta}$

$w_{A}=\frac{E T_{\max } \alpha}{(1+\alpha)}\left(\frac{\bar{\theta}}{\phi}\right)^{\beta_{a}}$

$\beta_{a}$ is an empirical vegetation parameter featuring in radiative ET term.

It should be noted that drainage does not provide spatially distributed information, and is already quantified in the EHB model (see Section 2.3). Hence we purposely ignore it in the EMT model. Therefore Eq. (2) is simplified as:

$\theta=\frac{w_{L} \theta_{L}+w_{R} \theta_{R}+w_{A} \theta_{A}}{w_{L}+w_{R}+w_{A}}$

The spatial variance $\left(\sigma^{2}\right)$ reproduced by LFI and ETI is given by

$\sigma_{L}^{2}=\left[\frac{Z_{r} K_{s, h}\left(\frac{\bar{\theta}}{\phi \Lambda}\right)^{\gamma_{h}}\left(\frac{\bar{\theta} \sigma_{L I I}}{\Lambda}\right)}{Z_{r} K_{s, h}\left(\frac{\bar{\theta}}{\phi \Lambda}\right)^{\gamma_{h}}+\frac{E T_{\max }}{(1+\alpha)}\left(\frac{\bar{\theta}}{\Pi \phi}\right)^{\beta_{r}}+\frac{E T_{\max } \alpha}{(1+\alpha)}\left(\frac{\bar{\theta}}{\phi}\right)^{\beta_{a}}}\right]^{2}$

$\sigma_{R}^{2}=\left[\frac{\frac{E T_{\max }}{(1+\alpha)}\left(\frac{\bar{\theta}}{\bar{\Pi} \phi}\right)^{\beta_{r}}\left(\frac{\bar{\theta} \sigma_{E T l}}{\Pi}\right)}{Z_{r} K_{s, h}\left(\frac{\bar{\theta}}{\phi \Lambda}\right)^{\gamma_{h}}+\frac{E T_{\max }}{(1+\alpha)}\left(\frac{\bar{\theta}}{\bar{\Pi} \phi}\right)^{\beta_{r}}+\frac{E T_{\max } \alpha}{(1+\alpha)}\left(\frac{\bar{\theta}}{\phi}\right)^{\beta_{a}}}\right]^{2}$ 
where $\sigma_{L F I}$ and $\sigma_{E T I}$ are the standard deviations of the LFI and ETI patterns, respectively. The relative importance of the two patterns is given by the ratio of the difference to the sum between the two variances through the pattern metric $N_{p}$ (Coleman and Niemann, 2013):

$N_{p}=\frac{\sigma_{L}^{2}-\sigma_{R}^{2}}{\sigma_{L}^{2}+\sigma_{R}^{2}}$

where $-1 \leq N_{p} \leq+1$. The $N_{p}$ pattern-metric helps interpret the dominant type of topographical dependence as follows:

a) $N_{p}=+1$ when all spatial variation of soil moisture is due to the lateral flow index (LFI);

b) $N_{p}=-1$ when all spatial variation of soil moisture is due to the radiative evapotranspiration index (ETI).

\section{Calibration and performance metrics of the proposed approach}

Calibration was performed by using random parameter sampling $(10,000$ random parameter combinations in each model) in a two-step approach. In the first step the parameters of the EHB model $\left(S_{h}, S_{w}, S^{*}, S_{f c}, \phi, K_{s, v}\right.$, and $\left.\gamma_{v}\right)$ were tuned on the observed (TDR) spatial-average near-surface soil moisture values. In the second step, the unknown parameters $\left(K_{s, h}, \gamma_{h}, \beta_{r}, \beta_{a}, \kappa_{\min }, \varepsilon\right.$, and $\left.\alpha\right)$ of the EMT model were calibrated on the observed (TDR) sparse soil moisture measurements. Both calibration steps based on the skill score were executed by maximizing the Nash-Sutcliffe Efficiency (NSE) index (Nash and Sutcliffe, 1970) expressed as a percentage after 10,000 model simulations by using random parameter combinations. The root mean squared deviation (RMSD in percentage) was also used to diagnose performance metrics. The two metrics were calculated by considering soil moisture values at all measurement locations and on all days of the measurement campaigns.

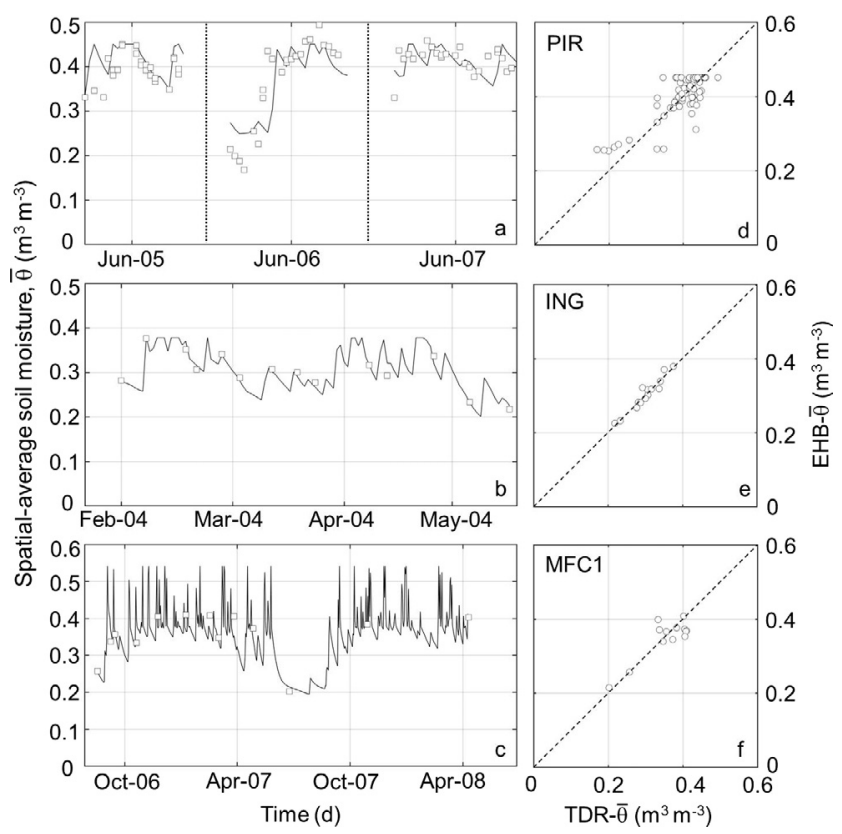

Fig. 3. EHB model performance: Left column - Comparison between measured (white squares) and simulated (black line) spatial-average soil moisture at a) PIR, b) ING and c) MFC1. The vertical dotted lines delimit three measurement periods in summer 2005, 2006, and 2007 at site PIR; Right column - 2D scatter plots of measured and simulated spatial-average soil moisture at d) PIR, e) ING and f) MFC1. The dashed lines represent the 1:1 line.
The performance of the EHB model is shown in Fig. 3, while Table 2 reports prior range and optimized values at the three experimental sites together with performance metrics (NSE and RMSD). The active depth $z_{r}$ was fixed at the length of TDR sensor rods used at the three sites.

At site PIR the optimized $\phi=0.45 \mathrm{~m}^{3} \mathrm{~m}^{-3}$ falls within the measurement range and can be considered acceptable as the EHB model is unable to characterize macropores on the surface organic layer. Moreover, the optimized value of $K_{s, v}$ is two orders of magnitude higher than the average saturated hydraulic conductivity (about $0.259 \mathrm{~m} \mathrm{~d}^{-1}$ ), measured by means of a Guelph permeameter (Penna et al., 2013). This high value is justified by the presence of macropores generated by earthworm biological activity, as observed by the authors. The EHB-simulated spatial-average soil moisture data are able to reproduce the drying and wetting dynamics fairly well in the range between $0.30 \mathrm{~m}^{3} \mathrm{~m}^{-3}$ and 0.45 $\mathrm{m}^{3} \mathrm{~m}^{-3}$, but a mismatch is observed for values above soil porosity and under very dry conditions (Fig. 3a). Note that model simulations in this site are assumed valid only in the snow-free period (typically May-October). Given these circumstances, the EHB model is able to mimic the observed values fairly well (Fig. 3d), as diagnosed by acceptable performance metrics reported in Table 2.

The model calibration at the ING site was executed over a short time-span (February to May 2004) and the optimized parameters belong to a silty clay loam class (Clapp and Hornberger, 1978) except saturated hydraulic conductivity which is higher than expected. Field capacity is $\theta_{f c}=0.33 \mathrm{~m}^{3} \mathrm{~m}^{-3}$ and corresponds to listed average values reported by Romano et al. (2011). Model performance is excellent as displayed in Fig. 3b. Even though the calibration was carried out for a short-term period and observed data vary within a limited range, we can consider model simulations very accurate. Modeled and observed spatial-average soil moisture data align along the 1:1 line (Fig. 3e) and we report a high value of NSE and low value of RMSD (Table 2).

The soil hydraulic characteristics optimized at the MFC1 site can be considered valid for a clay loam soil. Nasta et al. (2013) report a spatial-average $K_{s, v}=0.582 \mathrm{~m} \mathrm{~d}^{-1}$, as determined by laboratory methods. Indeed, most of the area is arable land subjected to soil tillage that may dramatically alter porosity and hydraulic conductivity on the surface layer (Romano and Nasta, 2016). The EHB model is able to reproduce spatial-average soil moisture dynamics covering at least an entire hydrologic year characterized by the typical seasonality of the Mediterranean climate. Closer inspection of Fig. $3 \mathrm{c}$ reveals the good performance of the modeled data that mimic the swift responses to rainfall occurrences in the wet season and the drydown trend in summer. The results are corroborated by the fair alignment of modeled and observed soil moisture in Fig. $3 \mathrm{f}$ and the satisfactory performance metrics reported in Table 2.

Table 3 reports optimized parameters and performance metrics pertaining to spatial distributed soil moisture patterns simulated by the EMT model. Fig. 4 offers a visual analysis in three illustrative examples by showing observed soil moisture values and simulated patterns of soil moisture in a specific date of measurement after model calibration.

At the PIR site the EHB-simulated spatial-average soil moisture is $0.39 \mathrm{~m}^{3} \mathrm{~m}^{-3}$ (35th measurement date), and the readily available topographic data should detect wet and dry areas in convex and divergent regions, respectively (Fig. 4a). Simulated driest soil moisture values (red to orange) mismatch the observed ones whereas soil moisture values above the spatial average (green) are well represented by the model. At the PIR site the overall performance of the downscaling procedure is fair (NSE $=30.3 \%$; RMSD $=6.4 \%$; see Table 3). Nevertheless, in this snow-dominated environment spatial variation of soil moisture induced by snowmelt and accumula- 
Table 2

Prior and optimized EHB-model parameter sets for each experimental site. The depth of modeled soil control volume $\left(z_{r}\right)$ is the length of TDR probes.

\begin{tabular}{|c|c|c|c|c|c|}
\hline & \multicolumn{5}{|l|}{ Range } \\
\hline & $\min$ & $\max$ & PIR & ING & MFC1 \\
\hline$S_{h}(-)$ & 0.00 & 0.10 & 0.003 & 0.005 & 0.024 \\
\hline$S_{w}(-)$ & 0.010 & 0.50 & 0.224 & 0.436 & 0.378 \\
\hline$S^{*}(-)$ & 0.60 & 1.00 & 0.989 & 0.978 & 0.994 \\
\hline$S_{f c}(-)$ & 0.40 & 0.90 & 0.962 & 0.867 & 0.708 \\
\hline$\phi\left(\mathrm{m}^{3} \mathrm{~m}^{-3}\right)$ & 0.40 & 0.60 & 0.451 & 0.384 & 0.523 \\
\hline$K_{s, v}\left(\mathrm{~m} \mathrm{~d}^{-1}\right)$ & 0.05 & 50 & 24.51 & 10.41 & 3.10 \\
\hline$\gamma_{v}(-)$ & 4 & 25 & 11.17 & 10.17 & 7.70 \\
\hline$z_{r}(\mathrm{~m})$ & & & 0.12 & 0.15 & 0.15 \\
\hline NSE\% & $-\infty$ & 100 & 61.64 & 91.73 & 65.64 \\
\hline RMSD\% & 0 & 100 & 4.07 & 1.18 & 3.28 \\
\hline
\end{tabular}

Table 3

Prior and optimized EMT-model parameter sets and performance metrics for each study catchment.

\begin{tabular}{|c|c|c|c|c|c|}
\hline & \multicolumn{5}{|l|}{ Range } \\
\hline & $\min$ & $\max$ & PIR & ING & MFC1 \\
\hline$K_{s, h}\left(\mathrm{~m} \mathrm{~d}^{-1}\right)$ & 0.05 & 50 & 14.85 & 43.23 & 36.25 \\
\hline$\gamma_{h}(-)$ & 1 & 15 & 9.96 & 1.93 & 7.68 \\
\hline$\beta_{r}(-)$ & 0.2 & 5 & 2.90 & 0.72 & 0.20 \\
\hline$\beta_{a}(-)$ & 0.2 & 5 & 1.77 & 3.58 & 2.23 \\
\hline$k_{\min }\left(\mathrm{m}^{-1}\right)$ & $-10^{6}$ & $\min k^{\dagger}$ & $-7,444$ & -693 & $-62,314$ \\
\hline$\varepsilon(-)$ & 1 & 3 & 1.07 & 2.62 & 2.67 \\
\hline$\alpha(-)$ & 0 & 0.74 & 0.65 & 0.42 & 0.38 \\
\hline NSE\% & $-\infty$ & 100 & 30.3 & 44.4 & 28.8 \\
\hline RMSD\% & 0 & 100 & 6.4 & 4.6 & 7.5 \\
\hline
\end{tabular}

${ }^{\dagger}$ Upper limit is set above observed minimum $k$ in each site.

tion dynamics was ignored in this study because the EHB model does not consider snow sublimation and melting processes.

At site ING, simulated soil moisture values above the spatial average are aligned along the water lateral-redistribution grid cells. Overall the best model performance is observed at ING that is affected by a relatively low discrepancy between observed and simulated spatially distributed soil moisture patterns (RMSD = 4.57\%). Both simulated and observed highest soil moisture values (above the spatial average equal to $0.30 \mathrm{~m}^{3} \mathrm{~m}^{-3}$ in the 8 th measurement date) are dominated by lateral flux (Fig. 4b), even though the observed soil moisture patterns do not unfortunately entirely cover the experimental area for model validation purposes.

The worst performance is observed at the MFC1 site (NSE = $28.8 \%$ ). In this case the EMT model is unable to fully exploit readily available topographic information as diagnosed by RMSD $=7.55 \%$. Nonetheless, as revealed by Fig. 4c, simulated soil moisture patterns (EHB-simulated spatial-average soil moisture is $0.35 \mathrm{~m}^{3}$ $\mathrm{m}^{-3}$ in the 8 th measurement date) tend to show wetter conditions on the north-facing slope with surface morphology that favors water accumulation. Such simulations are partly supported by the observed soil moisture patterns. This experimental area is the largest among the three fields and is characterized by a higher degree of heterogeneity in terms of spatial variability of land use and soil properties. The original assumption of uniform vegetation and soil properties attributed to the field is probably partly violated although the expected zone of wetness identified by topography represents fairly well the observed soil moisture values in wet conditions.

We recall that, on the one hand, increasing saturated horizontal hydraulic conductivity $\left(K_{s, h}\right)$ and empirical vegetation parameter featuring in radiative ET $\left(\beta_{r}\right)$ favor lateral flow and promote valley-dependent soil moisture patterns. On the other, hillslopedependent soil moisture patterns become more prevalent when $\gamma_{h}$ and $\varepsilon$ increase. The remaining terms $\left(\beta_{a}, \kappa_{\min }, \alpha\right)$ have little effect on the simulated moisture patterns (Coleman and Niemann, 2013).
We now evaluate the ability of the EMT model to reproduce the first and second moments of the frequency distribution of the observed soil moisture patterns, and the correlation coefficient between simulated and measured values of $\theta$. We refer to the decomposition of the NSE as follows (Gupta et al., 2009):

$$
\begin{aligned}
& \text { NSE }=2 \varphi r-\varphi^{2}-\psi^{2} \\
& \text { with } \\
& \varphi=\sigma_{\text {sim }} / \sigma_{\mathrm{obs}} \\
& \psi=\left(\mu_{\mathrm{sim}}-\mu_{\mathrm{obs}}\right) / \sigma_{\mathrm{obs}}
\end{aligned}
$$

where $\mu$ and $\sigma$ are the mean and standard deviation, respectively, of the observed (subscript "obs") and simulated (subscript "sim") soil moisture values, $r$ is the correlation coefficient between simulated and measured soil moisture values, $\varphi$ compares observed and simulated spatial variability, and $\psi$ is the bias expressed in units of $\sigma_{\text {obs. }}$ The three components of NSE should be visualized in 3-D criteria space and best parameter set (optimal point) is the one with the shortest Euclidean distance with the ideal point $(r=1, \varphi=1$ and $\psi=0$ ). For convenience, we assume the term $\psi$ as null and hypothesize a perfect match between simulated and observed spatial-average soil moisture (ideal performance of the EHB model). Therefore, we reduce the dimensional criteria space in 2-D and compare trade-off with the ideal point $(r=1$ and $\varphi=1)$, indicating a perfect match between simulated and observed soil moisture patterns. Fig. 5 shows the RMSD\% values (colorbar from blue to yellow, indicating low and high discrepancies, respectively) pertaining to all 10,000 random parameter combinations scattered as a function of $\varphi$ and $r$ for the three experimental sites. The optimal point is represented by the black asterics $(r=1, \varphi=1)$ and the optimal parameter set is the closest to the ideal point.

Best (or least worse) model performance is given in the ING site with the shortest Euclidean distance between ideal and optimal points $(r=0.67, \varphi=0.72)$. The PIR site has a lower correlation coef- 
ficient but higher capability via the EMT model of explaining observed spatial variability of soil moisture patterns $(r=0.56, \varphi$ $=0.88$ ). At the MFC1 site the EMT-simulated spatial variability of
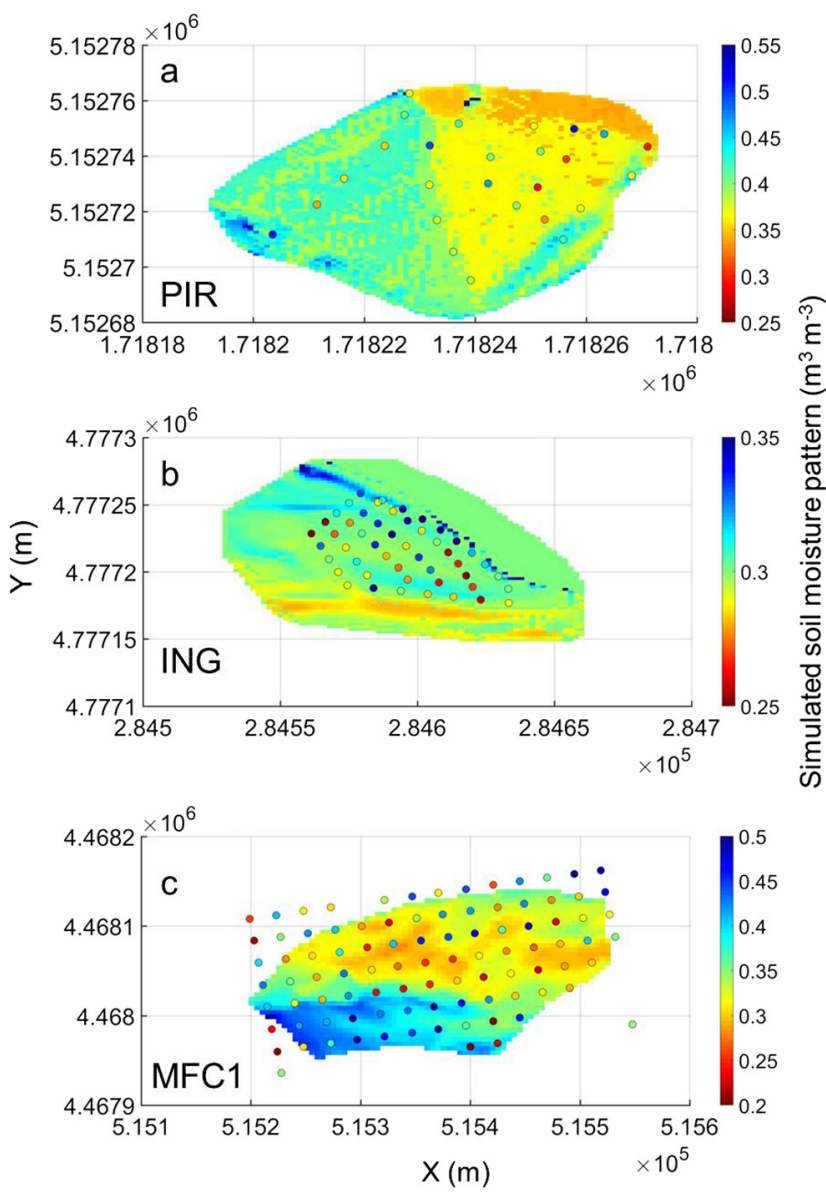

Fig. 4. EMT-model performance: Representative measured (circles) and simulated (maps) soil moisture patterns at a) PIR, b) ING and c) MFC1 when spatial-average (EHB-simulated) soil moisture is $0.39 \mathrm{~cm}^{3} \mathrm{~cm}^{-3}, 0.30 \mathrm{~cm}^{3} \mathrm{~cm}^{-3}, 0.35 \mathrm{~cm}^{3} \mathrm{~cm}^{-3}$, respectively.

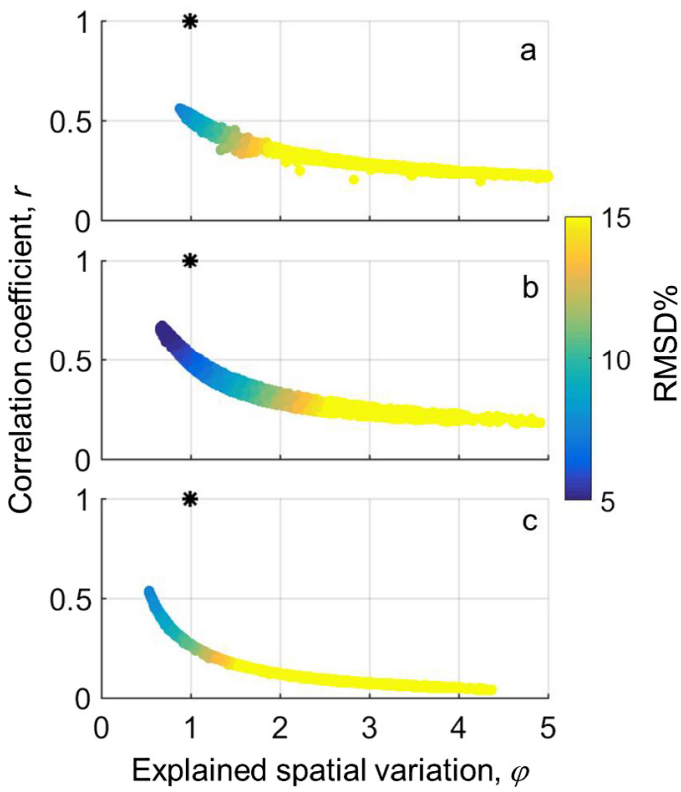

Fig. 5. Relationship of RMSD with $\varphi$ and $r$ at a) PIR, b) ING and c) MFC1. The ideal point $(\varphi=1, r=1)$ is represented by the black asterisk. soil moisture patterns is only about half of that observed ( $r=$ 0.53, $\varphi=0.54$ ). However, Gupta et al. (2009) warn on the interplay between $r$ and $\varphi$ with the risk of underestimating the spatial variability in the soil moisture patterns. Nevertheless, the EMT model exploits only spatially distributed terrain attributes and ignores the spatial information on soil and vegetation (Ranney et al., 2015). Indeed, the lowest RMSD\% values are distributed for $\varphi<1$, implying that the EMT model is unable to reproduce spatial variability higher than the measured one. Given the large area of the MFC1 site, it would be better to include spatial variation of soil and vegetation parameters in the EMT model (Ranney et al., 2015).

\section{Results and discussion}

\subsection{Analysis of spatio-temporal variance in soil moisture patterns}

The spatial variation of soil moisture patterns explained by the EMT model is interpreted through the $N_{p}$ pattern metric (calculated with Eqs. (8) and (9)) depending on parameter combinations for $\varphi<1$ (quantified through the boxplots shown in Fig. 6). This allowed us to run a sensitivity analysis of the EMT model only for the theoretically valid and plausible parameter sets. As shown by Fig. 6, the type of topographic dependence varies with spatialaverage soil moisture at all sites. In general, the lowest $\bar{\theta}$-values are associated to $N_{p}=-1$, implying that the ET index is the dominant pattern of spatial variation of soil moisture patterns.

Conversely all spatial variation is due to lateral flow and valley dependence $\left(N_{p}=+1\right)$ when $\bar{\theta}$-values are highest. The range of plausible $N_{p}$ values is very low under extreme saturation

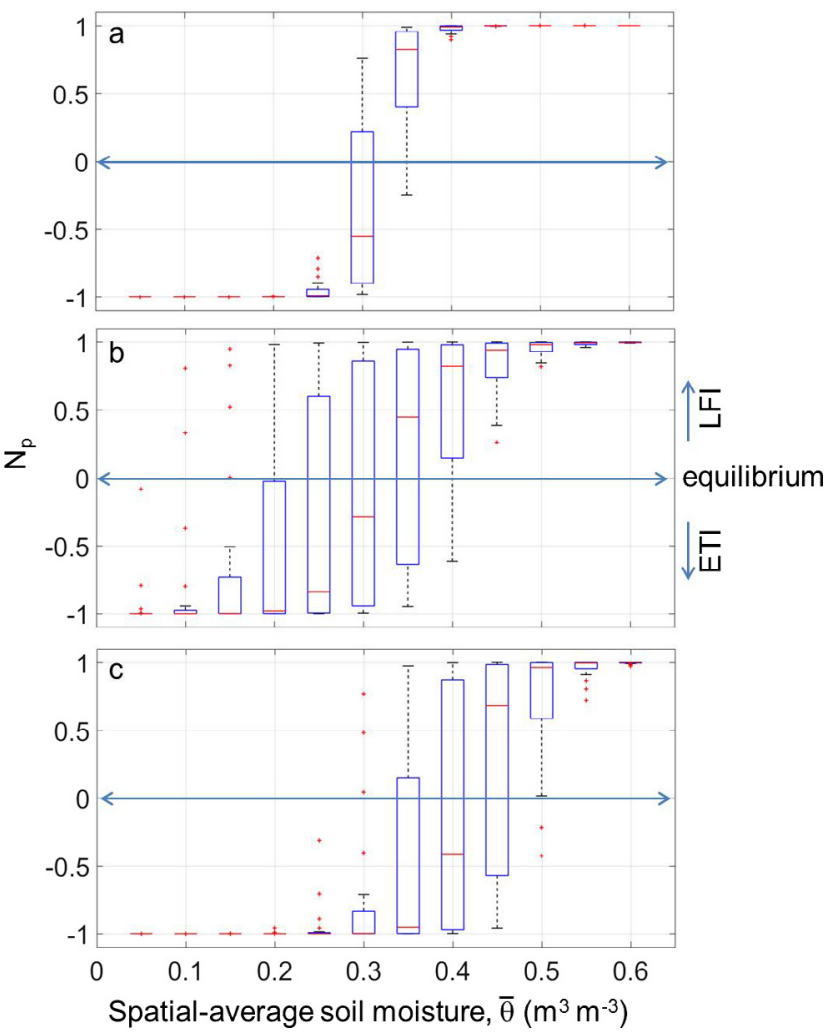

Fig. 6. Box plots of $\mathrm{N}_{\mathrm{p}}$-values obtained by using only parameter combinations for $\varphi<1$ at a) PIR, b) ING and c) MFC1. The horizontal red lines are the median values, vertical dashed black lines represent the whiskers, and red crosses denote the outliers. The horizontal blue arrows in each subplot denote the equilibrium $\left(N_{p}=0\right)$ between ETI and LFI. (For interpretation of the references to color in this figure legend, the reader is referred to the web version of this article.) 
conditions (whether dry or wet). Yet we observe a wide range of $N_{p}$ values in the transition from dry to wet conditions (or vice versa). The median values of the boxplots (horizontal red lines inside the boxes) represent the most probable types of topographic dependence that vary with spatial-average soil moisture values which in turn depend on climate seasonality. In this regard, Fig. 6 needs to be visualized together with Fig. 7 which shows spatial-average soil moisture values aggregated at monthly averages by using available historical time series of daily rainfall $(R)$ and reference evapotranspiration $\left(E T_{\max }\right)$ (see Table 1 ).

The spatial-average soil storage and soil moisture associated to the aridity index (AI) in each season are summarized in Table 4.

The snow-free summer period at the PIR site (delimited by the orange vertical dashed lines in Fig. 7d) is characterized by spatial-average soil moisture spanning between $0.35 \mathrm{~m}^{3} \mathrm{~m}^{-3}$ and $0.45 \mathrm{~m}^{3} \mathrm{~m}^{-3}$. Seasonal patterns are all humid (AI $>0.75$ and $\bar{\theta}>0.40 \mathrm{~m}^{3} \mathrm{~m}^{-3}$ ) at PIR, even though strong seasonality of soil moisture was reported in a high mountain catchment in Switzerland (Rößler and Löffler, 2010). Soil moisture patterns at PIR (Fig. 6a) are mostly dominated by the valley-dependent index (LFI). We report $\bar{S} \geq 0.90$ which is slightly below field capacity $\left(S_{f c}=0.962\right.$; see Table 2$)$. Since the EHB model misses spatial-average soil moisture below $0.30 \mathrm{~m}^{3} \mathrm{~m}^{-3}$ (see Figs. 3 and 6), we dictate that the proposed model is valid only under humid conditions at the PIR site.

At the ING site both LFI and ETI contribute to the spatial variation of soil moisture patterns. The lateral flow process is more important in wet conditions (fall and winter with $\mathrm{AI}>0.75$ ) since positive $N_{p}$ values are associated to $\bar{\theta}>0.30 \mathrm{~m}^{3} \mathrm{~m}^{-3}$ ( $\bar{S}$ around 0.80 which is close to field capacity, $S_{f c}=0.867$; see Table 2$)$. Median $N_{p}$ values are 0.44 and 0.82 for $\bar{\theta}=0.35 \mathrm{~m}^{3} \mathrm{~m}^{-3}$ and $\bar{\theta}=0.40 \mathrm{~m}^{3}$ $\mathrm{m}^{-3}$, respectively (Fig. 6b). The spatial variation of soil moisture patterns is mostly explained by the radiative ET process under a sub-humid (spring with $0.65<\mathrm{AI}<0.75$ and $\bar{S}=0.68$ ) and semiarid (summer with $0.20<\mathrm{AI}<0.50$ and $\bar{S}=0.51$ ) climate (Fig. $7 \mathrm{~b}$ ). In summer, soil saturation approaches the wilting point $\left(S_{w}=\right.$ 0.436 ; see Table 2 ). This test site proved to be the most highperforming, with an intra-annual change of LFI and ETI dominance periods that reflect seasonal variability of boundary forcing data in the Mediterranean climate. This degree of temporal instability may also be explained by a high value of $K_{s, h}$ and a $\beta_{r}$ value close to 0.8 (Table 3), as recommended by Coleman and Niemann (2013). Temporal instability in the EMT model is a consequence of the dominance of lateral flow during the two humid seasons (winter and fall) since this hydrological process controls valley-dependent soil moisture patterns. By contrast, during the dry season in the Mediterranean climate, hillslope-dependent soil moisture patterns are mainly influenced by radiative ET which controls vertical water flux along the soil profile. As shown by Fig. 7b, the dry season is characterized by water deficit with monthly $E T_{\max }$ surpassing monthly sums of rainfall.

At MFC1 the ETI patterns explain the majority of spatial variability of soil moisture throughout the year. We observe negative $N_{p}$ values for $\bar{\theta}<0.40 \mathrm{~m}^{3} \mathrm{~m}^{-3}$ and positive $N_{p}$ values for $\bar{\theta}>0.40$ $\mathrm{m}^{3} \mathrm{~m}^{-3}$ (Fig. 6c). However, spatial-average soil moisture is expected to be lower than $0.30 \mathrm{~m}^{3} \mathrm{~m}^{-3}$ (Fig. 7f) occurring under a semi-arid climate $\left(\bar{S}\right.$ in summer is close to the wilting point, $S_{w}$ $=0.378$; see Table 2 ). The increase in spatial-average soil moisture during the humid seasons (fall and winter with $\mathrm{AI}>0.75$ and $\bar{S}$ close to field capacity, $S_{f c}=0.708$; see Table 2) is not sufficient to switch the type of topographic dominance. Therefore valley dependence is never dominant at this site.

EMT-simulated soil moisture patterns at the three experimental sites are displayed in Fig. 8 for a wide spectrum of spatial-average soil moisture $\left(0.3,0.4\right.$ and $\left.0.5 \mathrm{~m}^{3} \mathrm{~m}^{-3}\right)$. The EMT model at PIR identifies two different patterns, one with lower and the other with higher soil moisture values spread over the divergent and convergent portions of the hillslope, respectively. Such patterns are preserved for all spatial-average moisture states by corroborating time stability of soil moisture patterns at the PIR site. ING is characterized by valley bottoms with water accumulation zones and low spatial variability in the rest of the area. Finally, at MFC1 wetter areas are detected in the north-facing slopes of the subcatchment, demonstrating that radiation-related dominant processes are maintained for all values of spatial-average soil moisture.

\subsection{Analysis of time instability of soil moisture patterns at ING}

The time instability of simulated soil moisture patterns detected at the ING site will be analyzed in greater depth in order to respond to the scientific question posed in Section 2.2: "what is the relationship between seasonal climate indicators and dominant type of topographic dependence?". In the graphs of Fig. 9 we compare the historical records (47 years) of seasonal AI values (blue bars in the left column) with the corresponding seasonal distributions of daily ( $90 \mathrm{~d}, 92 \mathrm{~d}, 92 \mathrm{~d}, 91 \mathrm{~d}$ in winter, spring, summer and fall, respectively) $N_{p}$ values (boxplots in the right column). The wettest seasons are winter and fall with the majority of AI values $>0.75$ (seasonal $R$ higher than seasonal $E T_{\max }$ ) and dominance
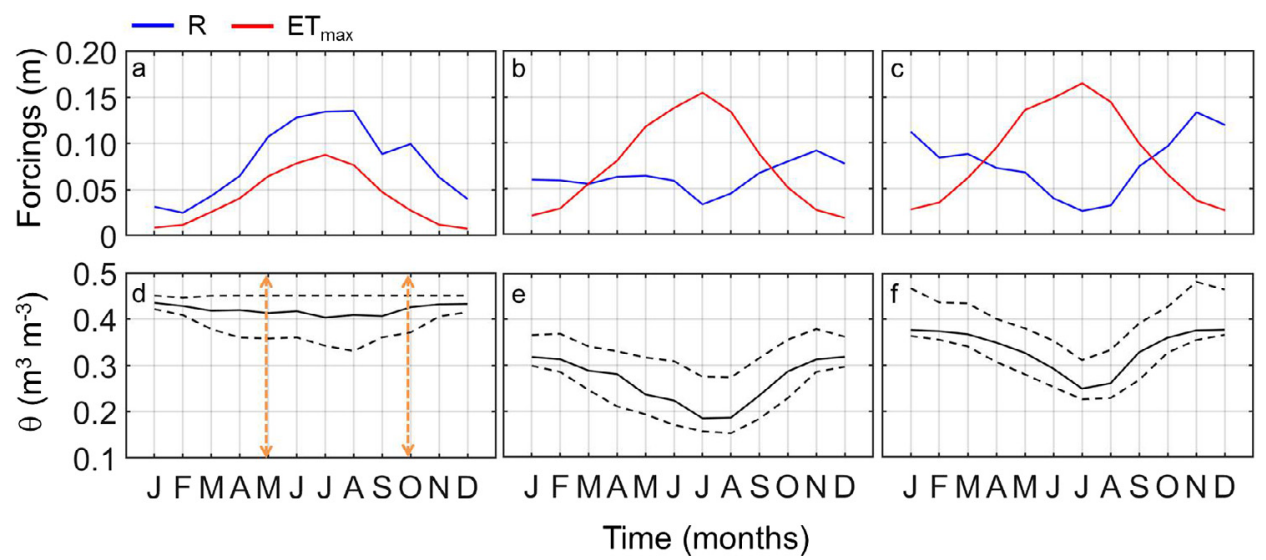

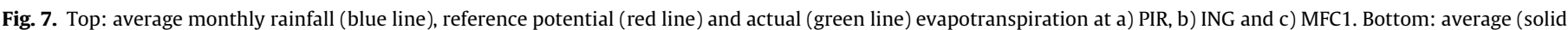

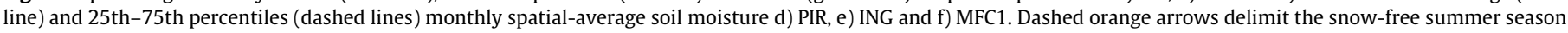
at the PIR site. (For interpretation of the references to color in this figure legend, the reader is referred to the web version of this article.) 
Table 4

Seasonal values of historical aridity index (AI) together with the spatial-average soil-water saturation ratio $(\bar{S})$ and soil moisture $(\bar{\theta})$ for each study catchment.

\begin{tabular}{|c|c|c|c|c|c|c|c|c|c|}
\hline & \multicolumn{3}{|l|}{ PIR } & \multicolumn{3}{|l|}{ ING } & \multicolumn{3}{|l|}{ MFC1 } \\
\hline & $\begin{array}{l}\text { AI } \\
(-)\end{array}$ & $\begin{array}{l}\bar{S} \\
(-)\end{array}$ & $\begin{array}{l}\bar{\theta} \\
\mathrm{m}^{3} \mathrm{~m}^{-3}\end{array}$ & $\begin{array}{l}\text { AI } \\
(-)\end{array}$ & $\begin{array}{l}\bar{S} \\
(-)\end{array}$ & $\begin{array}{l}\bar{\theta} \\
\mathrm{m}^{3} \mathrm{~m}^{-3}\end{array}$ & $\begin{array}{l}\text { AI } \\
(-)\end{array}$ & $\begin{array}{l}\bar{S} \\
(-)\end{array}$ & $\begin{array}{l}\bar{\theta} \\
\mathrm{m}^{3} \mathrm{~m}^{-3}\end{array}$ \\
\hline Winter $^{\dagger}$ & 3.03 & 0.94 & 0.42 & 2.18 & 0.81 & 0.31 & 2.97 & 0.70 & 0.36 \\
\hline Spring $^{\dagger}$ & 1.86 & 0.91 & 0.41 & 0.66 & 0.68 & 0.26 & 0.61 & 0.62 & 0.33 \\
\hline Summer & 1.76 & 0.90 & 0.40 & 0.40 & 0.51 & 0.20 & 0.33 & 0.49 & 0.26 \\
\hline Fall $^{\dagger}$ & 4.33 & 0.93 & 0.42 & 2.28 & 0.79 & 0.31 & 2.44 & 0.69 & 0.36 \\
\hline
\end{tabular}

Season with snowfall events.

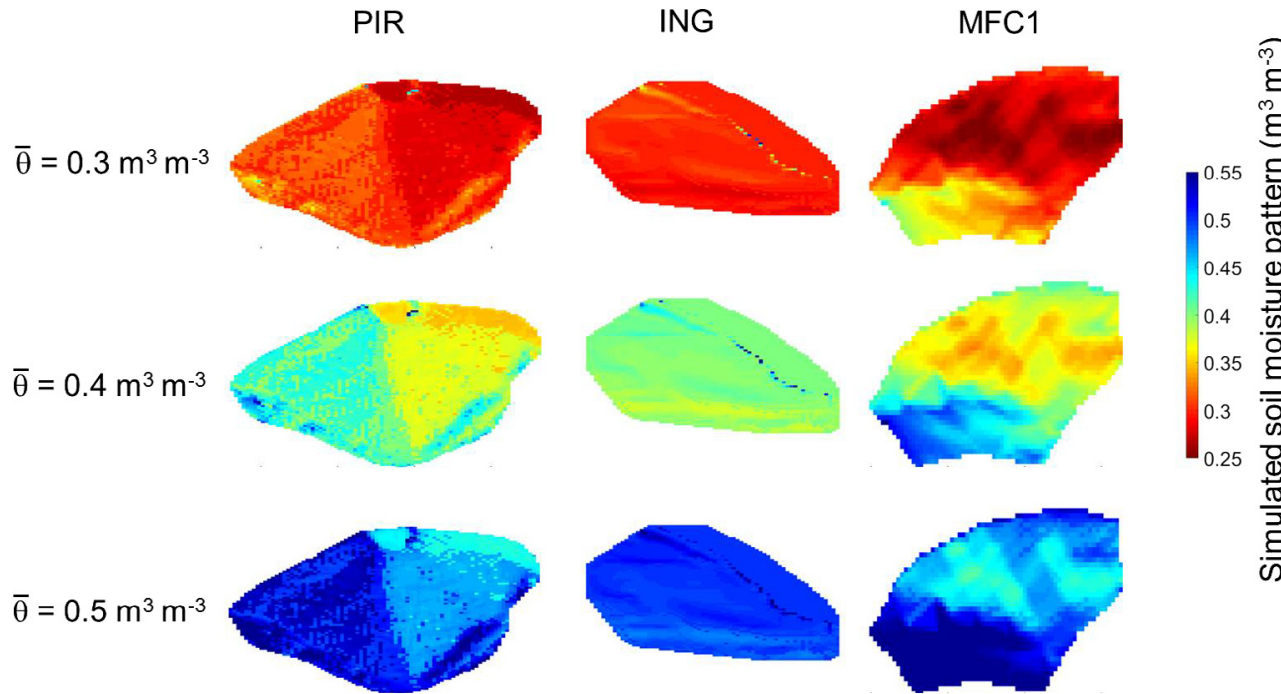

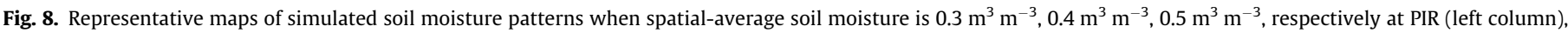
ING (central column) and MFC1 (right column).

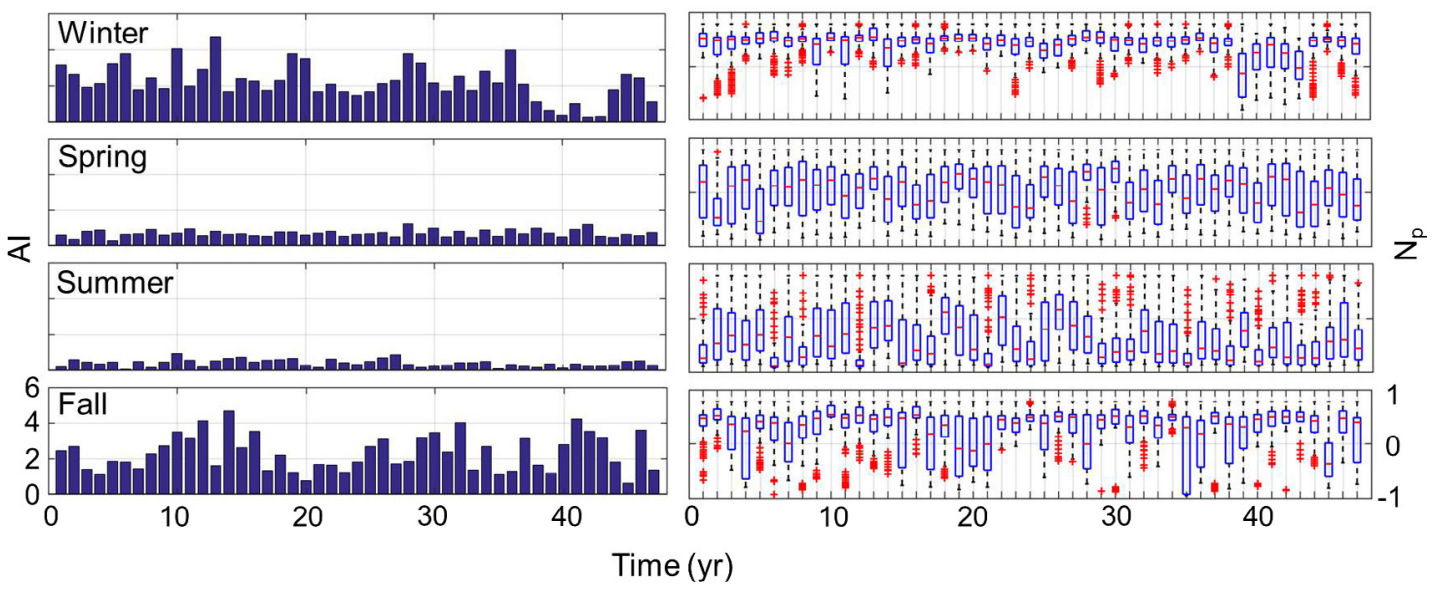

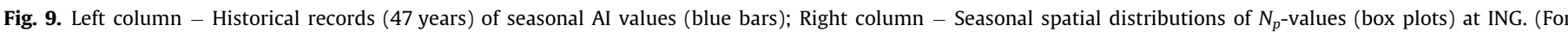
interpretation of the references to color in this figure legend, the reader is referred to the web version of this article.)

of $N_{p}$ values $>0$, diagnosing valley-dependent soil moisture patterns when surface and subsurface lateral flow occurs.

The distributions of $N_{p}$ values are wider in the fall season that is probably affected by antecedent dry conditions. It is worth noting that there are four cases in winter and two cases in fall with AI values $<1$ and median values of corresponding $N_{p}$ distributions around zero, indicating equilibrium between ETI and LFI dominance (see Fig. 6). The driest seasons are spring and summer when lateral redistribution is minimum and water fluxes are essentially vertical. In spring we observe $N_{p}$-distributions approximately centered around zero, implying an equilibrium between hillslopedependent and valley-dependent soil moisture patterns. Nonetheless in summer the spatial variability of soil moisture is mostly dominated by ETI patterns (negative $N_{p}$-values), hence governed by the potential solar radiation index $\left(I_{p}\right)$.

The relationship between seasonal $\mathrm{AI}$ and median value of the $N_{p}$ distributions (red horizontal line in the boxplots of Fig. 9, assumed as the most probable value) is displayed in Fig. 10. On 


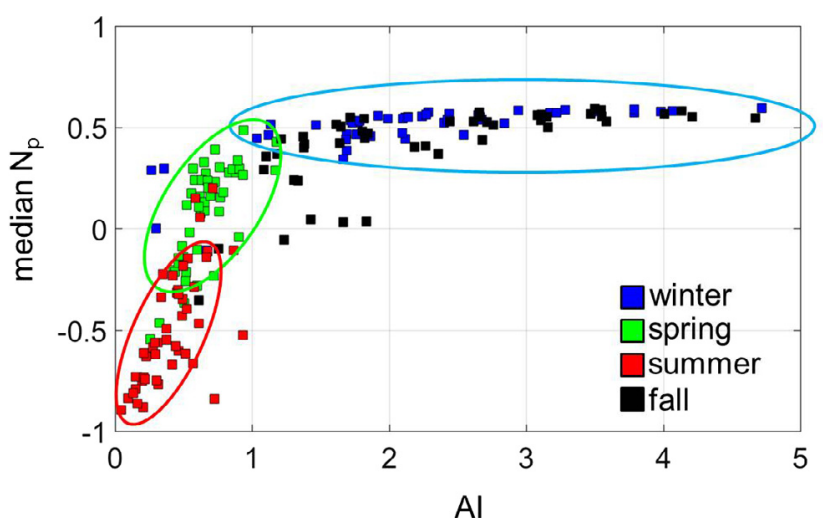

Fig. 10. Relationship between seasonal AI and median value of $N_{p}$-distributions. The red, green and light blue ellipses group summer, spring and winter + fall values, respectively. (For interpretation of the references to color in this figure legend, the reader is referred to the web version of this article.)

the one hand, high AI values in winter and fall are related to valleydependent soil moisture patterns (median $N_{p}$ values are about 0.5 ) that remain approximately steady in time (cluster of data included in the light blue ellipse). On the other hand, the median $N_{p}$ values decrease with drier AI values in spring (data cluster in the green ellipse) and especially in summer (data cluster in the red ellipse). Yet all median $N_{p}$ values in summer are negative and imply soil moisture patterns exclusively dominated by ETI patterns, whereas the majority of median $N_{p}$ values (30 out of 47 ) in spring are positive and indicate valley-dependent soil moisture patterns.

\section{Conclusions}

This study explored the feasibility of downscaling field-scale spatial-average soil moisture to plot-scale soil moisture patterns based on easily available terrain features and long records of climate forcing data. The proposed model was calibrated with sporadic and sparse measurements of ground-based soil moisture values at three small experimental sites with low topographical relief. The results offer the opportunity to interpret the timevariant sources of soil moisture spatial variability by considering the impact of dominant hydrological processes under dry and wet conditions. The experimental PIR site (hillslope characterized by high elevation, steep slope, humid summer) is dominated by time-invariant valley-dependent soil moisture patterns during the snow-free season (summer) when runoff frequently occurs. By contrast, the MFC1 site (sub-catchment characterized by clay loam texture, contrast between north-facing and south-facing slopes) located in southern Italy is dominated by time-invariant hillslope-dependent soil moisture fields that depend mostly on the potential solar radiation index. Interestingly, the calibrated set of EMT parameters at the ING site reproduce time instability and a switch between valley-dependent and hillslope-dependent soil moisture patterns that is subjected to climate seasonality. Therefore, in light of projected seasonal climate change, the topographic dependence of soil moisture patterns may be forecast. Since most climate projections warn of future increases in drought spells in the Mediterranean Belt (Norrant and Douguédroit, 2006), we expect increasing occurrences of hillslope-dependent soil moisture patterns along the estimated empirical relationship.

This approach offers a topographically induced deterministic representation of spatial variability of soil moisture tailored to model scale transfer from field to plot. In this study we assumed soil and vegetation features to be spatially uniform. Importantly, more ambitious downscaling procedures (i.e. from catchment to plot scale) require that due account be taken of the spatial variability of additional biophysical controlling factors. Future investigations should try to expand the proposed approach for large-scale applications with spatial-average soil moisture measured by remote sensing $(10-40 \mathrm{~km})$. In this case the EMT model has to be replaced by the most recent upgraded versions that also consider spatially distributed vegetation and soil properties.

This study essentially conceptualized the development of a modeling framework to downscale soil moisture. However, a more in-depth evaluation of its actual potential will be carried out in a subsequent paper with the availability of dense spatio-temporal information about soil moisture values and patterns obtained from new-generation ground-based sensors such as cosmic-ray probes and wireless sensor networks.

\section{Acknowledgments}

The study reported in this paper was partially supported by the MiUR-PRIN Project "Innovative methods for water resources management under hydro-climatic uncertainty scenarios" (grant 2010JHF437) and EU-LIFE+Project "ECOREMED - Implementation of eco-compatible protocols for agricultural soil remediation in the Litorale Domizio - Agro Aversano NIPS" (grant LIFE11-ENV/ IT/275). We also acknowledge the comments and suggestions of two anonymous reviewers which enhanced the quality of the current version of the paper.

\section{References}

Beaudette, D.E., Dahlgren, R.A., O'Geen, A.T., 2013. Terrain-shape indices for modeling soil moisture dynamics. Soil Sci. Soc. Am. J. 77, 1696-1710.

Bergström, S., Lindström, G., 2015. Interpretation of runoff processes in hydrological modelling-experience from the HBV approach. Hydrol. Process. 29, 3535-3545.

Blume, T., Zehe, E., Bronstert, A., 2009. Use of soil moisture dynamics and patterns at different spatio-temporal scales for the investigation of subsurface flow processes. Hydrol. Earth Syst. Sci. 13, 1215-1234.

Brocca, L., Morbidelli, R., Melone, F., Moramarco, T., 2007. Soil moisture spatial variability in experimental areas of central Italy. J. Hydrol. 333, 356-373.

Brocca, L., Melone, F., Moramarco, T., Morbidelli, R., 2009. Soil moisture temporal stability over experimental areas in central Italy. Geoderma 148, 364-374.

Brocca, L., Tullo, T., Melone, F., Moramarco, T., Morbidelli, R., 2012. Catchment scale soil moisture spatial-temporal variability. J. Hydrol. 422-423, 63-75.

Brocca, L., Ciabatta, L., Massari, C., Camici, S., Tarpanelli, A., 2017. Soil moisture for hydrological applications: open questions and new opportunities. Water 9, 140. https://doi.org/10.3390/w9020140.

Busch, F.A., Niemann, J.D., Coleman, M., 2012. Evaluation of an empirical orthogonal function - based method to downscale soil moisture patterns based on topographical attributes. Hydrol. Process. 26, 2696-2709.

Cheval, S., Dumitrescu, A., Birsan, M.-V., 2017. Variability of the aridity in the SouthEastern Europe over 1961-2050. Catena 151, 74-86.

Clapp, R.B., Hornberger, G.M., 1978. Empirical equations for some soil hydraulic properties. Water Resourc Res. 14, 601-604.

Castillo, A., Castelli, F., Entekhabi, D., 2015. Gravitational and capillary soil moisture dynamics for distributed hydrologic models. Hydrol. Earth Syst. Sci. 19, 1857 1869.

Coleman, M.L., Niemann, J.D., 2012. An evaluation of nonlinear methods for estimating catchment-scale soil moisture patterns based on topographic attributes. J. Hydroinf. 14 (3), 800-814. https://doi.org/10.2166/ hydro.2012.145.

Coleman, M.L., Niemann, J.D., 2013. Controls on topographic dependence and temporal stability in catchment-scale soil moisture patterns. Water Resour. Res. 49, 1625-1642.

Cosh, M.H., Stedinger, J.R., Brutsaert, W., 2004. Variability of surface soil moisture at the watershed scale. Water Resour. Res. 40, W12513.

Cowley, G.S., Niemann, J.D., Green, T.R., Seyfried, M.S., Jones, A.S., Grazaitis, P.J., 2017. Impacts of precipitation and potential evapotranspiration patterns on downscaling soil moisture in regions with large topographic relief. Water Resour. Res. 53. https://doi.org/10.1002/2016WR019907.

FAO (Food and Agriculture Organization of the United Nations - with UNESCO and WMO), 1977. World Map of Desertification. Food and Agricultural Organization (FAO), Rome.

Dimitrov, M., Vanderborght, J., Kostov, K.G., Debecker, B., Schulze Lammers, P., Damerow, L., Vereecken, H., 2015. Soil hydraulic parameters of bare soil plots with different soil structure inversely derived from L-band brightness temperatures. Vadose Zone J. https://doi.org/10.2136/vzj2014.09.0133. 
Famiglietti, J.S., Ryu, D., Berg, A.A., Rodell, M., Jackson, T.J., 2008. Field observations of soil moisture variability across scales. Water Resour. Res. 44, W01423. https://doi.org/10.1029/2006WR005804.

Gaur, N., Mohanty, B.P., 2013. Evolution of physical controls for soil moisture in humid and subhumid watersheds. Water Resour. Res. 49, 1244-1258.

Gupta, H.V., Kling, H., Yilmaz, K.K., Martinez, G.F., 2009. Decomposition of the mean squared error and NSE performance criteria: Implications for improving hydrological modelling. J. Hydrol. 377, 80-91.

Guswa, A.J., Celia, M.A., Rodriguez-Iturbe, I., 2002. Models of soil moisture dynamics in ecohydrology: a comparative study. Water Resour. Res. 38 (9), 1166. https:// doi.org/10.1029/2001WR000826.

Hargreaves, G.L., Hargreaves, G.H., Riley, J.P., 1985. Irrigation water requirements for Senegal River basin. J. Irrig. Drain. Eng. 111, 265-275.

Hoehn, D.C., Niemann, J.D., Green, T.R., Jones, A.S., Grazaitis, P.J., 2017. Downscaling soil moisture over regions that include multiple coarse-resolution grid cells. Rem. Sens. Environ. 199, 187-200.

Hu, W., Si, B.C., 2014. Revealing the relative influence of soil and topographic properties on soil water content distribution at the watershed scale in two sites. J. Hydrol. 516, 107-118.

Jonard, F., Mahmoudzadeh, M., Roisin, C., Weihermüller, L., André, F., Minet, J., Vereecken, H., Lambot, S., 2013. Characterization of tillage effects on the spatial variation of soil properties using ground-penetrating radar and electromagnetic induction. Geoderma 207, 310-322.

Joshi, C., Mohanty, B.P., 2010. Physical controls of near-surface soil moisture across varying spatial scales in an agricultural landscape during SMEX02. Water Resour. Res. 46, W12503.

Korres, W., Koyama, C.N., Fiener, P., Schneider, K., 2010. Analysis of surface soil moisture patterns in agricultural landscapes using empirical orthogonal functions. Hydrol. Earth Syst. Sci. 14, 751-764.

Laio, F., Porporato, A., Ridolfi, L., Rodriguez-Iturbe, I., 2001. I. Plants in watercontrolled ecosystems: Active role in hydrologic processes and response to water stress II. Probabilistic soil moisture dynamics. Adv. Water Resour. 24 (7), 707-724.

Meyles, E., Williams, A., Ternan, L., Dowd, J., 2003. Runoff generation in relation to soil moisture patterns in a small Dartmoor catchment, Southwest England. Hydrol. Process. 17, 251-264.

Mittelbach, H., Seneviratne, S.I., 2012. A new perspective on the spatio-temporal variability of soil moisture: temporal dynamics versus time-invariant contributions. Hydrol. Earth Syst. Sci. 16, 2169-2179.

Mohanty, B.P., Cosh, M.H., Lakshmi, V., Montzka, C., 2017. Soil moisture remote sensing: state-of-the-science. Vadose Zone J. 16. https://doi.org/10.2136/ vzj2016.10.0105.

Nash, J.E., Sutcliffe, J.V., 1970. River flow forecasting through conceptual models part I - A discussion of principles. J. Hydrol. 10, 282-290.

Nasta, P., Kamai, T., Chirico, G.B., Hopmans, J.W., Romano, N., 2009. Scaling soil water retention functions using particle-size distribution. J. Hydrol. 374, 223234.

Nasta, P., Romano, N., Chirico, G.B., 2013. Functional evaluation of a simplified scaling method for assessing the spatial variability of soil hydraulic properties at the hillslope scale. Hydrol. Sci. J. 58, 1-13.

Nasta, P., Palladino, M., Ursino, N., Saracino, A., Sommella, A., Romano, N., 2017. Assessing long-term impact of land-use change on hydrological ecosystem functions in a Mediterranean upland agro-forestry catchment. Sci. Total Environ. 605-606, 1070-1082.

Norrant, C., Douguédroit, A., 2006. Monthly and daily precipitation trends in the Mediterranean. Theor. Appl. Climatol. 83, 89-106.

Pachepsky, Y., Hill, R.L., 2017. Scale and scaling in soils. Geoderma 287, 4-30.

Peng, J., Loew, A., Merlin, O., Verhoest, N.E.C., 2017. A review of spatial downscaling of satellite remotely sensed soil moisture. Rev. Geophys. 55. https://doi.org/ 10.1002/2016RG000543.

Penna, D., Borga, M., Norbiato, D., Dalla Fontana, G., 2009. Hillslope scale soil moisture variability in a steep alpine terrain. J. Hydrol. 364, 311-327.

Penna, D., Tromp-Van Meerveld, H.J., Gobbi, A., Borga, M., Dalla Fontana, G., 2011. The influence of soil moisture on threshold runoff generation processes in an alpine headwater catchment. Hydrol. Earth Syst. Sci. 15, 689-702.

Penna, D., Brocca, L., Borga, M., Dalla Fontana, G., 2013. Soil moisture temporal stability at different depths on two alpine hillslopes during wet and dry periods. J. Hydrol. 477, 55-71.
Penna, D., Mantese, N., Hopp, L., Borga, M., Dalla Fontana, G., 2015. Spatio-temporal variability of piezometric response on two steep alpine hillslopes. Hydrol. Process. 29, 198-211.

Perry, M.A., Niemann, J.D., 2007. Analysis and estimation of soil moisture at the catchment scale using EOFs. J. Hydrol. 334 (3-4), 388-404.

Poltoradnev, M., Ingwersen, J., Streck, T., 2016. Spatial and temporal variability of soil water content in two regions of southwest Germany during a three-year observation period. Vadose Zone J. https://doi.org/10.2136/vzj2015.11.0143.

Qiu, J., Mo, X., Liu, S., Lin, Z., 2014. Exploring spatiotemporal patterns and physical controls of soil moisture at various spatial scales. Theor. Appl. Climatol. 118, $159-171$.

Qu, W. Bogena, H. Huisman, J.A. Vanderborght, J. Schuh, M., Priesack, E. Vereecken, H., 2015. Predicting subgrid variability of soil water content from basic soil information. Geophys. Res. Lett. 42, 789-796.

Ranney, K.J., Niemann, J.D., Lehman, B.M., Green, T.R., Jones, A.S., 2015. A method to downscale soil moisture to fine resolutions by using topographic, vegetation, and soil data. Adv. Water Resour. 76, 81-96.

Romano, N., 2014. Soil moisture at local scale: measurements and simulations. J. Hydrol. 516, 6-20.

Romano, N., Nasta, P., 2016. How effective is bimodal soil hydraulic characterization? Functional evaluations for predictions of soil water balance. Eur. J. Soil Sci. 67, 523-535.

Romano, N., Palladino, M., Chirico, G.B., 2011. Parameterization of a bucket model for soil-vegetation-atmosphere modeling under seasonal climatic regimes. Hydrol. Earth Syst. Sci. 15, 3877-3893.

Rößler, O, Löffler, J., 2010. Potentials and limitations of modelling spatio-tempora patterns of soil moisture in a high mountain catchment using WaSiM-ETH. Hydrol. Process. 24, 2182-2196.

Schröter, I., Paasche, H., Dietrich, P., Wollschläger, U., 2015. Estimation of catchment-scale soil moisture patterns based on terrain data and sparse TDR measurements using a fuzzy C-means clustering approach. Vadose Zone J. https://doi.org/10.2136/vzj2015.01.0008.

Shin, Y., Mohanty, B.P., 2013. Development of a deterministic downscaling algorithm for remote sensing soil moisture footprint using soil and vegetation classifications. Water Resour. Res. 49. https://doi.org/10.1002/wrcr.20495.

Spinoni, J., Vogt, J., Naumann, G., Carrao, H., Barbosa, P., 2015. Towards identifying areas at climatological risk of desertification using the Köppen-Geiger classification and FAO aridity index. Int. J. Climatol. 35, 2210-2222.

Swarowsky, A., Dahlgren, R.A., Tate, K.W., Hopmans, J.W., O’Geen, A.T., 2011 Catchment-scale soil water dynamics in a Mediterranean-type oak woodland. Vadose Zone J. 10, 800-815.

Vereecken, H., Huisman, J.A., Bogena, H., Vanderborght, J., Vrugt, J.A., Hopmans, J.W. 2008. On the value of soil moisture measurements in vadose zone hydrology: a review. Water Resour. Res. 44, W00D06. https://doi.org/10.1029/ 2008WR006829.

Vereecken, H., Huisman, J.A., Pachepsky, Y., Montzka, C., van der Kruk, J., Bogena, H. Weihermüller, L., Herbst, M., Martinez, G., Vanderborght, J., 2014. On the spatiotemporal dynamics of soil moisture at the field scale. J. Hydrol. 516, 76-96.

Vereecken, H., Huisman, J.A., Hendricks Franssen, H.J., Brüggemann, N., Bogena, H. Kollet, S., Javaux, M., van der Kruk, J., Vanderborght, J., 2015. Soil hydrology: Recent methodological advances, challenges, and perspectives. Water Resour. Res. 51, 2616-2633.

Werbylo, K.L., Niemann, J.D., 2014. Evaluation of sampling techniques to characterize topographically-dependent variability for soil moisture downscaling. J. Hydrol. 516, 304-316.

Western, A.W., Zhou, S., Grayson, R.B., McMahon, T.A., Blöschl, G., Wilson, D.J., 2004 Spatial correlation of soil moisture in small catchments and its relationship to dominant spatial hydrological processes. J. Hydrol. 286, 113-134.

Wilson, D.J., Western, A.W., Grayson, R.B., 2004. Identifying and quantifying sources of variability in temporal and spatial soil moisture observations. Water Resour. Res. 40, W02507. https://doi.org/10.1029/2003WR002306.

Zhao, Y., Peth, S., Hallett, P., Wang, X.Y., Giese, M., Gao, Y.Z., 2011. Factors controlling the spatial patterns of soil moisture in a grazed semi-arid steppe investigated by multivariate geostatistics. Ecohydrology 4, 36-48.

Zucco, G., Brocca, L., Moramarco, T., Morbidelli, R., 2014. Influence of land use on soil moisture spatial-temporal variability and monitoring. J. Hydrol. https://doi.org/ 10.1016/j.jhydrol.2014.01.043. 